\title{
SOSIALISASI INSTALASI KELISTRIKAN SWER UNTUK PENERANGAN LUAR SERTA HEMAT ENERGI LISTRIK DI DUSUN CEPAKA DESA MANIKYANG - SELEMADEG - TABANAN
}

\author{
I G N Janardana ${ }^{1}$, I M Suartika ${ }^{2}$, A I Weking ${ }^{3}$, WG Ariastina ${ }^{4}$
}

\begin{abstract}
ABSTRAK
Banjar/Dusun Cepaka merupakan salah satu banjar di Desa Manikyang, Kecamatan Selemadeg Kabupaten Tabanan dimana Desa Manikyang dengan topografi di daerah pegunungan dengan kondisi jarak antar rumah penduduk dan jarak rumah dengan lokasi usaha seperti usaha ikan, kandang ayam, kandang babi, kandang sapi berjauhan. Jarak rumah dengan lokasi kolam/kandang tersebut membutuhkan penerangan luar untuk mempermudah jangkauan tersebut. Salah satu sistem kelistrikan yang dapat dilakukan dan membutuhkan biaya murah adalah dengan sistem kelistrikan SWER(Single wire earth return) .Disamping masalah keamanan instalasi listrik pengoperasian peralatan listrik seperti lampu, peralatan elektronik sangat penting disosialisasikan kepada masyarakat agar masyarakat menggunakan listrik secara tepat agar, hemat biaya listrik. Hasil kegiatan menghasilkan beberapa masyarakat mampu dan memahami : memasang instalasi penerangan luar yang dipasang di jalan umum, mengetahui pemeliharaan instalasi listrik yang benar dan memahami umur instalasi yang sesuai standar, memahami kondisi instalasi listrik rumahnya yang telah lewat dari standar yang diijinkan oleh PUIL 2011, untuk menghindari bahaya kebakaran akibat instalasi listrik yang sudah rusak, mampu melakukan penghematan energi sesuai kebutuhan dan waktu yang tepat. Masyarakat diberikan batasan-batasan dan jenis-jenis kabel yang boleh dipergunakan.
\end{abstract}

Kata Kunci Instalasi, SWER, Keselamatan, Hemat Energi

\begin{abstract}
Banjar / Dusun Cepaka is one of the banjar in Manikyang Village, Selemadeg Subdistrict, Tabanan Regency where Manikyang Village with topography in mountainous areas with conditions of distance between houses and distance of houses to business locations such as fish businesses, chicken coops, pig pens, and far away cow cages. The distance of the house to the location of the pond / enclosure requires external lighting to facilitate that range. One of the electricity systems that can be done and requires low cost is with the single wire earth return electricity system. Besides the security problems of electrical installations operating electrical equipment such as lights, electronic equipment is very important to be disseminated to the public so that people use electricity properly so that electricity cost. The results of the activity resulted in several communities being able and understanding: installing outdoor lighting installations installed on public roads, knowing the maintenance of electrical installations that were correct and understanding the age of the installation according to the standard, understanding the condition of their electrical installations which had exceeded the standards permitted by PUIL 2011, avoid fire hazards due to damaged electrical installations, able to save energy according to the needs and the right time. Communities are given restrictions and types of cables that may be used.Abstrak juga ditulis dalam bahasa Inggris.
\end{abstract}

Keywords: Installation, SWER, Safety, Save Energy.

\footnotetext{
${ }^{1}$ Program Studi Teknik Elektro, Fakultas Teknik, Universitas Udayana, janardana@unud.ac.id

${ }^{2}$ Program Studi Teknik Elektro, Fakultas Teknik, Universitas Udayana

${ }^{3}$ Program Studi Teknik Elektro, Fakultas Teknik, Universitas Udayana

${ }^{4}$ Program Studi Teknik Elektro, Fakultas Teknik, Universitas Udayana
} 


\section{PENDAHULUAN}

\subsection{Analisis Situasi}

Banjar/Dusun Cepaka merupakan salah satu banjar di Desa Manikyang, Kecamatan Selemadeg Kabupaten Tabanan dimana Desa tersebut dengan batas desa sebagai berikut : Sebelah utara Desa Wanagiri, sebelah Timur Desa Megati, sebelah Selatan Desa Selemadeg dan sebelah barat Desa Pupuan Sawah. Banjar Cepaka, Desa Manikyang dengan topografi di daerah pegunungan dengan kondisi jarak antar rumah penduduk dan jarak rumah dengan lokasi usaha seperti usaha ikan, kandang ayam, kandang babi, kandang sapi berjauhan. Jarak rumah dengan lokasi kolam/kandang tersebut membutuhkan penerangan luar untuk mempermudah jangkauan tersebut. Salah satu sistem kelistrikan yang dapat dilakukan dan membutuhkan biaya murah adalah dengan sistem kelistrikan SWER(Single wire earth return) (Budiman, dkk,2000., Handoko, 2000., Harten, 1991).PUIL 2011).

Disamping masalah keamanan instalasi listrik pengoperasian peralatan listrik seperti lampu, peralatan elektronik sangat penting disosialisasikan kepada masyarakat agar masyarakat menggunakan listrik secara tepat agar, hemat biaya listrik dan juga sangat penting untuk masyarakat lain yang belum teraliri listrik dapat juga menikmatinya.

Berdasarkan permasalahan tersebut sistem SWER(Single wire earth return) perlu disosialisasikan kepada masyarakat Banjar Cepaka untuk dapat menghemat biaya pemasangan instalasi listrik dan terlistriki secara merata sehingga kegiatan perekonomian masyarakat khususnya masyarakat pedesaan yang perekonomiannya masih kurang dapat berjalan dengan baik. Disamping penggunaan sistem tersebut masyarakatnya perlu diberikan pemahaman penggunaan listrik secara efisien sehingga dapat menghemat energi listrik yang berdampak pada peningkatan perekonomiannya.

Maka perlu dilakukan pengabdian kepada masyarakat agar menggunakan listrik secara tepat hemat biaya listrik.

Berdasarkan permasalahan di atas maka tim pengabdian melaksanakan pengabdian di Banjar Tingkih Kerep dengan metode ceramah menggunakan alat peraga pengoperasian dan penggunaan peralatan listrik yang baik dan benar seperti : bahaya listrik, pengoperasian peralatan, hemat energi maupun pemeliharaan instalasi listrik.

\subsection{Perumusan Masalah}

Rumusan masalah dalam pengabdian masyarakat ini adalah bagaimana menyampaikan informasi tentang cara pemasangan instalasi listrik dan instalasi listrik SWER(Single wire earth return) yang baik dan benar sehingga dapat memberikan pencahayaan secara merata dan mampu menggunakan listrik secara hemat energi yang berujung pada peningkatan perekonomian masyarakat.

\subsection{Tujuan Kegiatan}

Adapun tujuan kegiatan pengabdian kepada masyarakat Banjar Cepaka, Desa Manikyang adalah sebagai berikut :

1. Supaya masyarakat bisa memelihara instalasi listrik yang benar agar terhindar dari bahaya listrik.s 
2. Supaya masyarakat bisa memanfaatkan dan pemasangan sistem SWER secara baik dan benar, sehingga dapat memberikan pencahayaan secara merata sampai pada tempat usahanya/kandang.

3. Supaya masyarakat bisa menghemat energi listrik yang dapat menghemat biaya dan dapat meningkatkan perekonomiannya.

\subsection{Manfaat Kegiatan}

Manfaat Pengabdian Masyarakat ini bagi masyarakat Banjar Cepaka, Desa Manikyang adalah diharapkan masyarakat dapat memelihara instalasi listrik yang benar agar terhindar dari bahaya listrik, mengenal instalasi listrik SWER baik dalam pemasangan maupun pengoperasiannya, sehingga dapat memberikan pencahayaan secara merata hingga ke lokasi usahanya serta masyarakat mampu menghemat energi listrik agar biaya yang dikeluarkan untuk kebutuhan listrik lebih hemat. Manfaat bagi Fakultas Teknik, adalah menambah wawasan tim Fakultas Teknik untuk mengaplikasikan ilmunya.

\subsection{Pemecahan Masalah}

Pemecahan masalah dilakukan sebagai berikut:

1. Memberikan penjelasan mengenai cara pemasangan dan pengoperasian instalasi listrik yang benar dengan alat peraga.

2. Memberikan penjelasan mengenai cara pemasangan dan pengoperasian sistem kelistrikan SWER.

3. Pemasangan alat peraga sebagai contoh instalasi sesuai standar PUIL 2011.

4. Membuat dan pemasangan stiker tentang bahaya listrik dan stiker hemat energi.

\section{METODE PELAKSANAAN}

Tim Pengabdian Kepada Masyarakat telah melakukan kegiatan sebagai berikut :

1. Memberikan ceramah kepada masyarakat konsep instalasi kelistrikan yang baik dan benar sesuai PUIL 2011 dengan memperagakan alat peraga instalasi listrik sehingga anggota masyarakat bisa menyaksikannya secara langsung instalasi listrik yang benar, cara penyambungan kabel, pemasangan isolasi, dan lain-lain.

2. Memberikan ceramah kepada masyarakat konsep instalasi kelistrikan SWER(Single wire earth return) yang baik dan benar sesuai standar.

3. Memperagakan peralatan instalasi listrik yang berstandar sesuai PUIL 2011sehingga anggota masyarakat bisa menyaksikannya secara langsung.

4. Memasang stiker-stiker tentang bahaya listrik, pemasangan instalasi serta stiker hemat energi listrik pada rumah penduduk dan tempat usaha maupun pada tempat-tempat umum.

5. Mengadakan diskusi dan tanya jawab tentang sistem instalasi listrik dan cara penghematan energy listrik.

Melakukan evaluasi beberapa kali ke desa hasil sosialisasi yang telah dilakukan 


\section{HASIL DAN LUARAN YANG DICAPAI}

\section{A. Hasil}

Untuk mendapatkan hasil pada kegiatan pengabdian masyarakat ini dilakukan pemecahan masalah sebagai berikut :

1. Melakukan iIdentifikasi instalasi listrik di masyarakat yang belum sesuai standar PUIL seperti penggunaan kabel NYF, pengoperasian stop kontak(kotak kontak) menumpuk melebihi aturan, isolasi tidak standar, cara penyambungan kabel, pengoperasian lampu berlebih dan lain-lain.

2. Melakukan identifikasi lokasi kelompok tani ikan maupun ternak.

3. Memperbaiki instalasi listrik pada salah satu instalasi yang salah tentang penyambungan kabel, isolasi sebagai contoh instalasi yang benar ke masyarakat.

4. Penanaman kabel tanam sesuai aturan/standar sekaligus sebagai contoh yang dapat ditiru oleh masyarakat.

5. Pemasangan stiker-stiker tentang hemat energi, stiker penggunaan stop kontak yang salah, stiker penggunaan stop kontak yang benar pada dinding rumah ke seluruh rumah-rumah penduduk serta pada tempat-tempat umum.

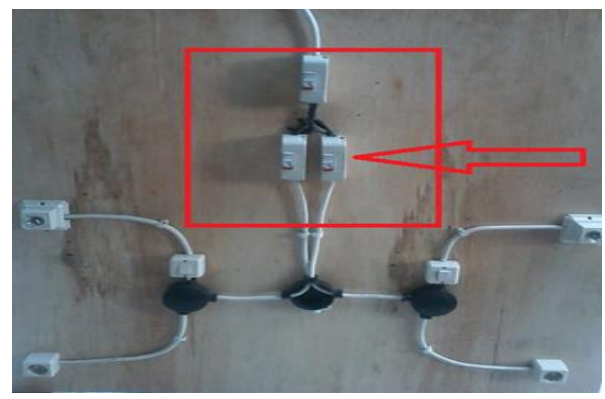

Gambar 1 Foto Alat Peraga yang Digunakan sosialisasi

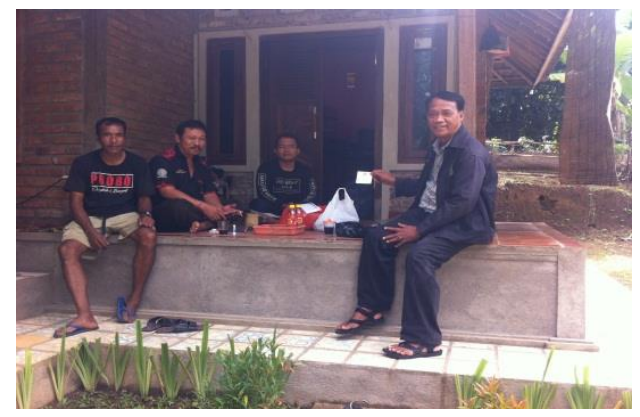

Gambar 2 Foto Sosialisasi Langsung ke Rumah Masyarakat Pelanggan listrik 
Sosialisasi Instalasi Kelisrikan SWER untuk Penerangan Luar Serta Hemat Energi Listrik di Dusun Cepaka Desa Manikyang Selemadeg Tabanan

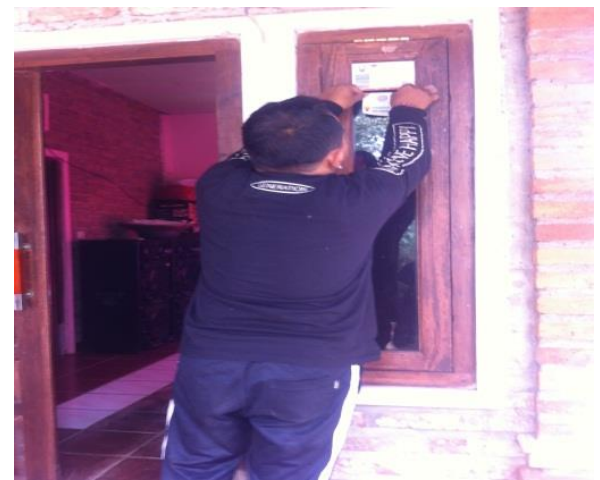

Gambar 3 Foto Kegiatan Masyarakat Memasang Stiker Bahaya Listrik dan Stiker Hemat Energi

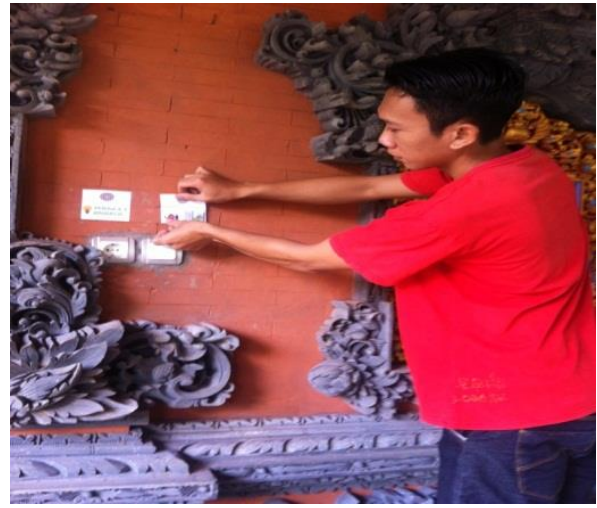

Gambar 4 Foto Sekeha Teruna-Teruni ikut Sosialisasi di Balai Banjar

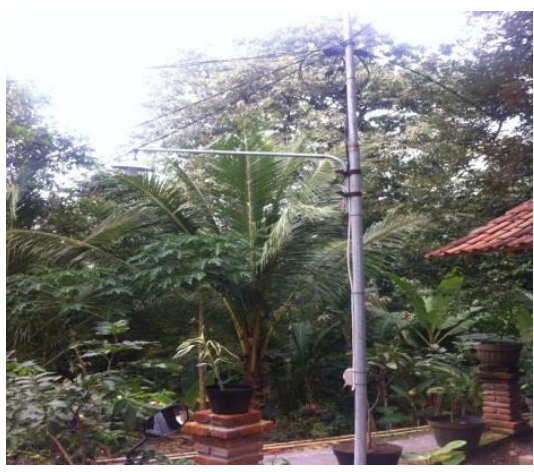

Gambar 5 Kegiatan Sosialisasi Penerangan Luar

6. Memberi contoh mengukur tahanan pembumian pada beberapa instalasi rumah tinggal dan fasilitas umum serta memberikan sosialisasi fungsi pembumian tersebut.

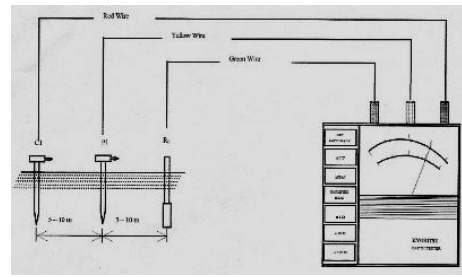

Gambar 8 Rangkaian Pengukuran Tahanan Pentanahan 
Hasil pelaksanaan kegiatan pengabdian masyarakat yang dilakukan di Desa Manikyang adalah sebagai berikut :

1. Beberapa masyarakat mampu dan memahami memasang instalasi penerangan luar yang dipasang di jalan umum.

2. Masyarakat mengetahui pemeliharaan instalasi listrik yang benar dan memahami umur instalasi yang sesuai standar.

3. Beberapa masyarakat memahami kondisi instalasi listrik rumahnya yang telah lewat dari standar yang diijinkan oleh PUIL 2011, sehingga masyarakat sudah menyiapkan diri untuk merenovasi instalasi listriknya untuk menghindari bahaya kebakaran akibat instalasi listrik yang sudah rusak.

4. Masyarakat mampu melakukan penghematan energi dengan mengoperasikan beberapa peralatan elektronik rumah tangga seperti Magic Jar, kulkas dan lain-lain sesuai kebutuhan dan waktu yang tepat.

5. Masyarakat diberikan batasan-batasan dan jenis-jenis kabel yang boleh dipergunakan.

\section{B.Luaran yang dicapai}

Secara umum khalayak sasaran kegiatan pengabdian masyarakat ini adalah seluruh pelanggan listrik dan pengguna listrik dan kelompok tani di Banjar Cepaka Manikyang, Selemadeg, Tabanan.

Luaran yang dicapai dalam pengabdian ini adalah :

1. Publikasi ilmiah di SNASTEK

2. Buletin Udayana Mengabdi

3. Pemasangan stiker

4. Masyarakat mampu/memahami memasang instalasi penerangan luar

Perubahan perilaku masayarakat pengguna listrik yang dapat menghemat energi listrik, pengoperasian peralatan listrik dan peralatan elektronik rumah tangga yang benar.

\section{KESIMPULAN DAN SARAN}

\subsection{Kesimpulan}

1. Masyarakat sudah mendapatkan sosialisasi dalam bentuk ceramah dan menyaksikan demontrasi dengan alat peraga instalasi listrik yang benar dan jenis-jenis kabel yang sesuai standar, serta pemasangan instalasi SWER.

2. Masyarakat mampu mengoperasikan peralatan elektronik rumah tangga dengan efisien sehingga dapat menghemat energi.

3. Masyarakat bersama-sama memasang stiker-stiker hemat energi dan penggunaan stop kontak yang benar di rumah-rumah penduduk dan fasilitas umum sebagai upaya mengajak masyarakat untuk hemat energi dan menggunakan instalasi listrik sesuai standar.

\subsection{Saran}

Saran yang bisa diberikan dari kegiatan pengabdian kepada masyarakat di Desa Manikyang khususnya Banjar Cepaka, Selemadeg, Tabanan adalah :masyarakat diharapkan menggunakan peralatan-peralatan listrik yang hemat energi, penggunaan 
peralatan instalasi listrik sesuai standar, pemeriksaan instalasi listrik secara berkala dan teratur dan penyambungan instalasi listrik harus oleh yang ahli di bidangnya, serta mampu memasang instalasi SWER yang benar ke tempat-tempat ternaknya.

Blank (11pt)

\section{UCAPAN TERIMA KASIH}

Blank (11pt)

Puji syukur kepada Ida Sang Hyang Widhi Wasa / Tuhan Yang Maha Esa, karena semua berkah dan rahmatnya, sehingga layanan ini terlaksana dengan baik. Kami juga ingin mengucapkan terima kasih kepada Universitas Udayana, Fakultas Teknik, Departemen Teknik Elektro Unud dan tim yang melayani dan semua audiens yang telah berhasil dalam layanan ini .

Blank (11pt)

Blank (11pt)

\section{DAFTAR PUSTAKA}

Blank (11pt)

Budiman, M. Dkk. 2000. Panduan Instalasi Listrik Untuk Rumah Berdasarkan PUIL 2000. Jakarta : Yayasan Usaha Penunjang Tenaga Listrik Bekerja sama dengan Copper Development Centre. South East Asia.

Handoko, P. 2000. Pemasangan Instalasi Listrik Dasar. Yogyakarta : Kanisius.

Harten, PV. Terjemahan : Setiawan E. 1991. Instalasi Listrik Arus Kuat 1. Bandung : Bina Cipta.

Harten, PV. Terjemahan : Setiawan E. 1991. Instalasi Listrik Arus Kuat 2. Bandung : Bina Cipta.

Harten, PV. Terjemahan : Setiawan E. 1991. Instalasi Listrik Arus Kuat 3. Bandung : Bina Cipta.

-, 2011. Persyaratan Umum Instalasi Listrik ( PUIL 2011). Jakarta 